\title{
Twenty-first century global anthropogenic warming convective model
}

1 Neale R. Neelameggham PhD*

The Guru, IND LLC, South Jordan, UT, USA
Brian R. Davis PhD

President, Brian Davis Associates Consulting, Manvel, TX, USA
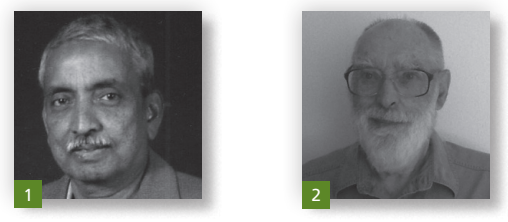

As today's world is rapidly trending to man-made or anthropogenic alternative energy while the total energy being utilized is increased, it is important to understand what happens to the energy generated and dissipated. The new energy conversions are mainly for electricity and for heating, cooling, lighting or chemical and metallurgical processes, all of which create thermal wastes, which are independent of the fuel or alternative energy. Present correlations will become obsolete in explaining atmospheric temperature variations when more and more renewable energy is used to create electricity, which in turn will continue the thermal emissions into the future, leaving only a small fraction as converted non-thermal stored energy. This is being addressed by a convective model in this paper that discusses the effect of thermal waste storage in the atmosphere - which leads to climatic change due to excess precipitation. The model shows that evapotranspiration changes play a major role in the atmospheric air mass constrained climate change. The extent of global mean temperature increase is a function of global population which increases thermal wastes or a function of sinusoidal variances in solar influx as noted by several scientists; the excess precipitation computations will fit any of the global mean temperature assumptions - from small to large increases.

\section{Introduction}

Approximately two-thirds of the Earth's surface is covered by ocean of buffered saline water and the remaining one-third is the land mass with a known mass of atmospheric air above it for a few kilometers. (The surface area of planet Earth $=5 \cdot 11 \times 10^{8} \mathrm{~km}^{2}$, atmospheric air mass $=5.15 \times 10^{18} \mathrm{~kg}-$ these are values from climate study literature and are summarized in http://en.wikipedia. org/wiki/Earth.) The planet Earth receives solar radiant energy input on a daily basis; varying with daytime and its location due to the planet's rotation on its own axis and around the sun. The Earth absorbs a small fraction of the energy and reflects most of the solar radiation into space for a global energy balance. The rotation causes the air mass to circulate and temperatures to vary during Earth's orbit. The circulation of air mass also helps in evaporating surface water - allowing water vapor into the atmosphere - which can condense into clouds and pour down back as rain or snow, which is called precipitation. The water vapor lingering in the air is the humidity of air. It is known that, at any temperature, there is a saturation humidity or maximum allowable water vapor content, beyond which there will be condensation of excess water. This variation in the temperatures and humidity of the surrounding air mass and the variation in precipitation is what called as the surrounding 'climate'; climate scientists take measurements, observe cloud movements and thereby predict the weather. These measurements and observations have resulted in computation of global average temperature, which is the mean of averages from the south pole to the north pole, as well as mapping of cloud patterns and many other variables.

Over the past century, most climate models have been based on only radiation input-output balance; the study presented here shows an alternate method based on the heat balance effect of manmade energy conversions. Since most of the energy conversions to date which are man-made (anthropogenic) have been based on carbonaceous fuel, the climate studies have included the effect of part of the combustion product, namely carbon dioxide $\left(\mathrm{CO}_{2}\right)$. The evaporation of surface water by circulating air mass causes the air temperature to drop - as this is another energy conversion 
phenomenon which has to meet the 'law of conservation of energy'. In this paper, the authors enhance a present-day climate model showing the simultaneous effects of man-made evaporative cooling as well as the combustion-related water vapor generation. In climate science parlance, water vapor constitutes more than $95 \%$ of the greenhouse gases with carbon dioxide contributing to most of the remaining 5\%. The main reason why carbon dioxide is called a greenhouse gas is that in the colder climes greenhouses were heated by a coke fire to avoid freezing and the plants grew much quicker with the extra carbon dioxide in the air.

This simple model/analysis can be easily understood: it is known how to keep warm from radiating heat and/or warm air in the winter. Those using air conditioners know that the room heat is dissipated as warm air by the condensers kept outside the room or house. Those who live in dry regions using swamp-coolers (evaporative coolers) know how warm air can be cooled by evaporation of water into the dry air, and that this evaporation improves by increasing surface area by dripping water as droplets clinging to pads or spraying as a mist. It is well known that dry air can pick up more moisture until it gets saturated. Also, it is known that increased humidity is invisible in the dry air. Hence, cold air coming into the house in winter from lack of good seals (paths of least resistance) needs more heat to keep warm. The specific heat of air is $1.02 \mathrm{~J} / \mathrm{g} /{ }^{\circ} \mathrm{C}$, adjusted for humidity with water vapor heat capacity and that of water is $4.18 \mathrm{~J} / \mathrm{g} /{ }^{\circ} \mathrm{C}$. Evaporative cooling calculations use the latent heat of evaporation of water which is $2257 \mathrm{~J} / \mathrm{g}$. The quantity or amount of heat is given by the mass $\times$ specific heat $\times$ temperature change. If the water changes phase to vapor the latent heats have to be added.

The mass of air around Earth is a known quantity that varies only by the humidity and minor changes in carbon dioxide. The global mean temperatures are mainly the temperature of the surrounding air mass near the surface of Earth. The statistics compiled by British Petroleum (BP) of global energy conversions are used to compute the additional heat added to the atmosphere (i.e., into the surrounding air mass) and how its temperature can vary because of this, and are compared with measured global mean temperatures and other climate observations.

As noted earlier, anthropogenic means 'created by people'. It is not surprising that there is a statistically significant correlation of growth in human population with time and in energy consumption, which is directly proportional to the population growth and its needs. These energy consumptions arise out of energy conversions. Most of the energy conversions for centuries have been from hydrocarbons - wood and other fossil fuels, in addition to water power. This would mean strong correlations exist with the simultaneous effects of water vapor and carbon dioxide on the air mass temperature and precipitation - or simply 'the climate'. Further, humans have evolved around converting most of these energy sources into 'electrical energy and other motive energy'. These 'secondary energy sources' in their applications, which improve the comfort of humanity, are converted to 'tertiary energy form' which is nothing but 'heat'. The 'law of conservation of energy' requires that this heat is stored unless dissipated into other forms of storage. The present paper is an enhanced version (in SI units) of the presentation made to TMS Energy Technology 2015 Symposium for international readers - that is, for an academic and industrial audience familiar with everyday units in American parlance of degrees Fahrenheit and BTUs (British Thermal Units).

Heat follows the path of least resistance and excessive heat tends toward the atmospheric air mass. This is global anthropogenic warming (GAW). Here, the authors will talk about the unsequestered (into water or solids) thermal emissions. They note that 'GAW is a form of energy storage which is proportional to the total energy conversions made irrespective of the source of that conversion, fuel or a renewable source'. Atmospheric air temperature is moderated by water vapor in the form of increasing specific humidity $\left(W_{\mathrm{s}}\right)$ and excess absorption $\left(W_{\mathrm{a}}\right)$. These combined together is noted as evapotranspiration and represented as $E_{\mathrm{v}}$. From this one can compute the excess precipitation, $P_{\mathrm{s}}$, which will increase or decrease from that which is due to solar insolence radiation on the ocean and other water bodies in the form of latent and specific heat content changes. In the twentieth century, the normal precipitation was considered to be about $2.7 \mathrm{~mm}$ of rain equivalent/day. ${ }^{2}$

The authors want to emphasize that the same atmospheric air temperature increase can be seen irrespective of different proportions of fuel and renewable alternative energy. Total energy conversion is used in creating the secondary energy sources of electricity and other motive energy. In other words, when there are more alternate energy conversions, such as solar/wind electricity displacing fossil fuel electricity, the atmosphere will still heat up to the extent of total thermal emissions even without an increase in the total carbon dioxide seen in air. The GAW calculations presented here are made using the heat balance of total energy conversions with atmospheric air mass heating by convection; with the air temperature changes observed with time.

When hydrocarbons are oxidized, the initial combustion products are water vapor and carbon dioxide. Water vapor is the major greenhouse gas - with reported effects as high as $95 \%$, the secondary effect comes from carbon dioxide; water vapor condensation requires shedding of its heat to the surrounding air, while water evaporation cools the air. The basic energy needs of any life form, whether it be plants, bacteria, animals or humans, revolve around the transfer of carbon dioxide and water - in and out of the life form.

\section{Initial GAW model development}

Initial work showed that water evaporation moderated the atmospheric temperature rise during the past 48 years (1965-2012) 
to an increase of only about $0.7^{\circ} \mathrm{C}$ compared to the $1.9^{\circ} \mathrm{C}$ of heating the atmospheric air by the 'swamp cooling' (evaporative cooling) effect from an added evaporation of surface waters. ${ }^{3,4}$ An earlier study of 'Heat Transfer Modeling of Global Anthropogenic Warming' was based on data of worldwide energy conversion statistics compiled by BP since $1965 .{ }^{5}$ It showed that while the carbon dioxide content went up by about 75 parts per million (ppm) into the atmospheric mass to a level of $~ 395 \mathrm{ppm}$ from $320 \mathrm{ppm}$, the total evapotranspiration equivalent of water vapor increase was a minimum of $740 \mathrm{ppm}$ and could have been as high as $1200 \mathrm{ppm}$ depending on the proportion of total anthropogenic energy conversion equivalent to the total thermal emission. The authors' evaluation was consistent with similar observations made by others on the specific humidity increase due to anthropogenic events. ${ }^{6}$

The study reported in this heat transfer modeling of $\mathrm{GAW}^{3,4}$ was carried out using the cumulative energy consumptions during the period 1965-2012 - applying stoichiometric balances on combustion of oil, natural gas and coal. This calculated that the carbon dioxide increase in the atmosphere should have been about $156 \mathrm{ppm}$, while water vapor should have increased by $152 \mathrm{ppm}$. Instead, only a $75 \mathrm{ppm}$ increase of carbon dioxide was seen in the atmosphere (the Mauna Loa Observatory data showed a change from about 320 to $395 \mathrm{ppm}$ ), and the role played by ocean absorption is documented by reports of the Intergovernmental Panel on Climate Change (IPCC). The role of carbon dioxide being absorbed by plants is not clear - other than some of the recent papers which discuss how global circulation and increased carbon dioxide have created new vegetation. ${ }^{7}$ This should have corresponding associated absorption of water vapor by plants during photosynthesis as well. Such observed changes in carbon dioxide are in line with the fundamentals of photosynthesis.

Plants produce glucose $\left(\mathrm{C}_{6} \mathrm{H}_{12} \mathrm{O}_{6}\right)$, a monomer needed for cellulose, using carbon dioxide and water $\left(\mathrm{H}_{2} \mathrm{O}\right)$ (liquid/vapor) (six moles each) for their growth and exhale oxygen $\left(\mathrm{O}_{2}\right)$; this is an endothermic reaction catalyzed by sunlight while taking away heat from the atmosphere. The heat of reaction is $+2826 \mathrm{~kJ} / \mathrm{g}$ mol glucose. Davis (in a 2014 private communication on the cooling effect of photosynthesis) has calculated that the glucose formation precursor reaction for cellulose of a tree can cause a cooling effect of about $2.9^{\circ} \mathrm{C}$ ( or $5 \cdot 2^{\circ} \mathrm{F}$ ) on a photosynthetic reaction basis - from mass of reactants to products. Thus some parts of the computed 'excess absorption and precipitation heating of surroundings' go toward this endothermic heat required for vegetation growth which is required for sustaining population growth. The observed overall vegetation growth is difficult to quantify - unless further stoichiometric studies are made of the mass of vegetation over any period of time, the quantification of which will be similar to population statistics. The other part of the 'excess absorption and precipitation heating of surroundings' is the increased precipitation from the nocturnal radiation to space cooling. The measurements of inorganic carbonate-bicarbonate balances in the oceans have been known from the beginning of the twentieth century - and have been summarized by Sverdrup et al. ${ }^{8}$ The buffer capacity of oceans allows the solubilization of carbon dioxide (an exothermic reaction). ${ }^{9}$ Oceans also intake carbon dioxide when cold and outgas when hot, similar to carbonated beverages and beer. This is from the simple partial pressure variations with temperatures of soluble gases. These have associated heats of concentration.

The authors' basic heat transfer model ${ }^{4}$ showed the need for a mathematical expression for the global mean temperature changes with the simultaneous effects from both water vapor and carbon dioxide - such as expressions shown by Hottel ${ }^{10}$ and Farag ${ }^{11}$ when they discussed the flue gas radiation heat transfer effects. Their flue gas radiation emissivity studies had a ratio of water vapor to carbon dioxide between 2:1 and 1:2, unlike the higher ratios of about 50:1 for the GAW heat transfers. (The average atmospheric absolute humidity in 1964 was about $16400 \mathrm{ppm}$ of water vapor at the $15^{\circ} \mathrm{C}$ average global mean temperature compared to $320 \mathrm{ppm}$ of carbon dioxide in air - that gives a 51:1 ratio.) Nasif Nahle is one of the few who had carried out an extension of Hottel's formula to compute the effects from simultaneous changes in carbon dioxide as well as water vapor in the atmosphere. ${ }^{12}$ In 1941 , Brooks ${ }^{13}$ carried out some experimental verification of radiation from gases and noted the difficulties involved.

The present-day radiative-convective modeling started evolving in the mid-1960s when Manabe and Wetherald ${ }^{14}$ used assumptions such as 'heat capacity of Earth is zero', and developed them to study the overall diurnal solar insolence heating and radiation (cooling) from Earth to space without having to worry about mass transfer or stoichiometric balances of how the carbon dioxide comes into the atmosphere. In their studies, the effects of water vapor, the major greenhouse gas (80-95\% of the greenhouse gas effect), were difficult to find due to the elusive but countless observed phenomena on specific humidity and cloud effects. These were called feedbacks compared to the greenhouse effect of carbon dioxide (which was minor and referred to as 'forcings'). The cloud seeding effects of excessive dust of nanoparticles were called the 'aerosol' feedback - which was used to explain large cooling effects of atmospheric temperature around volcanic eruptions, such as by Pinatubo in 1991, from such small quantities as 0.02 giga tons $(=20000000000 \mathrm{~kg})$ of sulfur dioxide $\left(\mathrm{SO}_{2}\right)$ and associated dust (which is only about 1.76 parts per billion sulfur dioxide in the atmospheric air of $1.78 \times 10^{17} \mathrm{~kg}$ moles).

During the 1980s and 1990s, correlations were made between increasing carbon dioxide in the atmosphere and increasing global mean temperatures; carbon dioxide levels were less elusive to measure as it is a non-condensable gas at atmospheric temperatures. Such correlations, based on short-term data of 25-30 years, started 


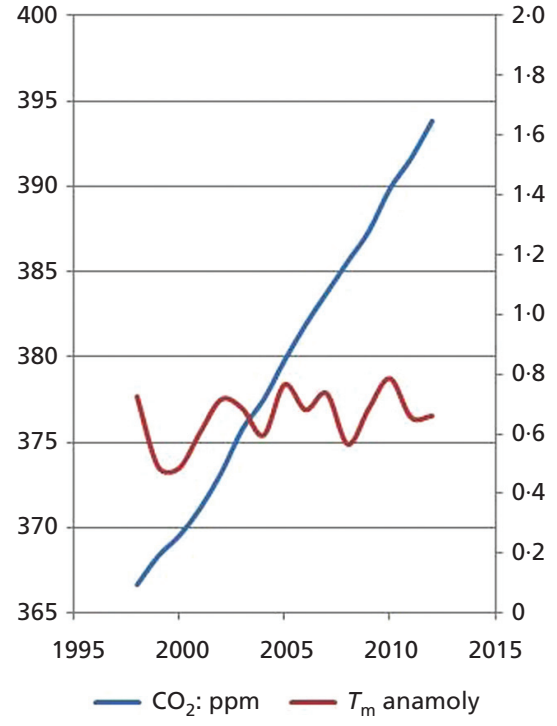

Figure 1. Global mean temperature with atmospheric $\mathrm{CO}_{2}$ - hiatus

to hit a roadblock during the last decade, which started to show a plateau of global mean temperatures, while the carbon dioxide level kept going up (Figure 1). This is called a 'hiatus' in climate literature during the recent past and is due to the ocean variability. The global mean temperature curve plateau can be seen in several references, while the carbon dioxide in the atmosphere kept increasing since $1997 .^{1}$

The authors will come back to the upward but cyclic nature of global mean temperature discussions later. The radiativeconvective model continued its evolution to include measurable cumulated temperature increase in the oceans by modifying parts of the assumptions; in the mid-1990s they were called 'ocean heat content-coupled models' and the models were denoted as Coupled Model Intercomparison Project or CMIP, ${ }^{15}$ and the version CMIP-5 formed the basis of the recent IPCC report of 2013. The authors want to note that the oceans always had absorbed some of the radiant heat input through the eons and many of the modern measurement techniques for recording these levels in the deep sections of the ocean were not available in the past. Solar evaporation of ocean water in creating sea salt has been known for over 2500 years. Passive solar heating of rocks also negates the assumption of zero heat capacity of Earth. It is simple mass-based heat balance from absorbed solar radiation by slab Earth and slab ocean. For the air to get heated or dissipated by radiation, it should have molecules with three or more atoms.

Modification of assumptions in these models still continues, along with forecasts of extinction. For example, climate changes and ocean level changes will be catastrophic if humans do not control carbon dioxide levels by continuing to use fossil fuels. Even though water vapor is the major greenhouse gas it is less harmful. These statements imply if fossil fuel energy conversions are avoided the Earth's atmosphere will cool down and climate changes will not happen Unsequestered thermal GAW can be reduced by modifying thermal emissions into air by suitable engineering as diverted thermal emissions into slab ocean or Earth with non-zero heat capacity. One of the methods of diverting thermal emissions into slab ocean is to capture them in water and let it flow out into the Earth through the rivers into the ocean - this is applicable to air-conditioner condensers as well as many a powerplant stack's gases and oil refinery's flares.

Compared to the daily solar insolence onto the land and oceans, the power equivalent of energy conversion by humans is a small fraction. This is similar to the conducted heat from Earth's core through the thick insulating mantle. But so is the change in the global mean temperature from one day to the next. It is the cumulative effect which is called the anthropogenic effect - such as global mean temperature increasing by $0.7^{\circ} \mathrm{C}$ in 45 years, which corresponds to only $4.3 \times 10^{-5}{ }^{\circ} \mathrm{C} /$ day. But this is an insignificant change in the terminology of climate models which omit human energy conversions as insignificant for convenience. These climate models that blame the carbon dioxide do not seem to make an attempt at simple chemical stoichiometric balances. Some widely published climate scientists continue to state that energy conversions by human beings are insignificant and heat balances from these energy conversions are not necessary compared to solar irradiance, but do not hesitate taking the carbon dioxide concentrations coming out of fossil fuel conversions while ignoring water vapor contributions from the same conversions. It is like living on deficit financing without having to balance the income and expense.

\section{GAW model development by IND LLC}

Many of the climate models show global energy balances on a daily basis based on solar power in and Earth's radiation out, but forget that the warming and increase of global mean temperature observations are time based. The global warming representation (GWR) reports can be used to compare with the GAW energy consumption on an annual basis in $\mathrm{J} / \mathrm{m}^{2}$ of Earth's surface energy quantity instead of the $\mathrm{W} / \mathrm{m}^{2}$ - power units, which is $\mathrm{J} / \mathrm{s} / \mathrm{m}^{2}$. The two quantities summed to represent global warming shown in various IPCC reports have been about the average ocean level increase of $1.8 \mathrm{~mm} /$ year and the heating up of the top $700 \mathrm{~m}$ of ocean by about $0 \cdot 11^{\circ} \mathrm{C}$ and can be calculated as (a) heat in joules for the melting glaciers on land causing ocean level increase averaging $1.8 \mathrm{~mm} /$ year since $1965,(b)$ the heat in joules for the heating up of the top $700 \mathrm{~m}$ of ocean by $0 \cdot 11^{\circ} \mathrm{C}$ in 48 years $\left(6 \cdot 2 \times 10^{-6}{ }^{\circ} \mathrm{C}\right.$ increase/day $)$. This cumulative total GWR from 1965 through 2012 is $1.29 \times 1023 \mathrm{~J}$. 
Global population statistics are available from UN demographic reports on a yearly basis, including projections to the year 2100. (World Population Estimates, see http://esa.un.org/ unpd/wpp/index.htm, accessed 06/07/2014, for further details.) The total energy consumption, $E_{\mathrm{t}}$, from BP statistics converted to joules from all energy sources can be expressed as $E_{\mathrm{t}}=-\left(1.1 \times 10^{20}\right)+\left(8.58 \times 10^{10}\right) \times$ population using the data since 1965, while the rapid growth seen since 1998 is expressed as $E_{\mathrm{t}}=\left(-4.6 \times 10^{20}\right)+\left(1.39 \times 10^{11}\right) \times$ population. The heat transfer model based on Neale's GAW theory was applied to each set of annual data since 1965, to arrive at additional correlations of the GAW convective model explaining anthropogenic warming with observed atmospheric temperatures.

The authors refer to this as the convective model based on massbased heat balances on the atmospheric air mass. Only since about 10 years ago has it been understood that air mass can become a possible constraint in climate modeling. The authors' convective model still includes the minor effects of spectral emissivity of carbon dioxide by stoichiometric basis compared to the major effects caused by water vapor.

\section{The convective model}

The stoichiometric basis of contained carbon and hydrogen is arrived at from the consumption of oil, natural gas and coal in each year to give the fuel-based emissions of carbon dioxide and $\mathrm{H}_{2} \mathrm{O}$ vapor into atmosphere. The calculated carbon dioxide addition is compared with Mauna Loa carbon dioxide increase to arrive at absorption by biological growth and in the oceans. The model calculated the amount of human-emitted carbon dioxide absorbed into plants and the absorption of carbon dioxide in the ocean to be about $39 \%$ in the 48 years. The authors' model does not compute the 'nanoparticles' or cloud seeding which may be required.

The mix of total energy consumption included the three main fossil fuels as well as the nuclear, the hydro and the renewable energy conversions. The authors' initial GAW model ${ }^{2,3}$ used only $67.5 \%$ of the energy consumption - which is due to the power-plant convention to report $32.5 \%$ thermal efficiency into electricity. But if one were to analyze what happens to the electricity they would note added thermal emissions arise out of that. The simple example of air conditioners taking the heat from inside of buildings and converting it to hot air, or thermal emissions, is known. This hot air follows the path of least resistance and rises into the atmosphere. Many of the metallurgical and chemical processes which use input energy release considerable enthalpy into the atmosphere, by radiation from the vessel's exterior heat losses or in the flue gas enthalpy. Only a small portion ends up being stored in the product for further use. Present-day combustion engine motive energy results in considerable thermal emissions. Future electric cars depend on thermal emissions from transmission lines (resistant heat losses), which bring the power for charging, and the battery loses heat during discharge from the internal and lead resistances. In essence, more than two-thirds of the electricity or gasoline power also create thermal emissions, leaving behind only about $9 \pm 2 \%$ of original energy conversion as non-thermal change (such as potential energy change or stored energy in other materials; an example is metal electrowinning). This necessitated the use of about an average of $91 \%$ of total energy - irrespective of the source of energy conversion - as total thermal emissions into atmospheric air heating. Note that the value of the heat coming from energy conversions can vary up to $\pm 2 \%$ with the non-thermal work being a small number. Again, this assumes that thermal emissions are unsequestered and end up heating the air. Present-day correlations will become obsolete in explaining atmospheric temperature variations when more and more renewable energy is used to create electricity which in turn creates thermal emissions in the future. This motivated the authors to develop the convective model further for projections into the future.

The heat balance carried out each year by convective heat increase in atmospheric air mass from these thermal emissions gives an initial value, $T_{\mathrm{e}}$, for the atmospheric mean temperature estimate. $T_{\mathrm{e}}-T_{\mathrm{b}}$, a constant atmospheric temperature base, is noted as DT1 and ranged from a lower value of $0.028^{\circ} \mathrm{C}$ in 1965 to a higher value of $0.092^{\circ} \mathrm{C}$ in 2012 , showing an observed cumulative increase of $0.066^{\circ} \mathrm{C}$ since 1965 compared to the anticipated cumulative increase of $2.79^{\circ} \mathrm{C}$. The value of observed global mean was computed using published 'anamoly' data from a base (here the base temperature used is $15^{\circ} \mathrm{C}$ ). Observed value anamolies include associated variations from nature, such as sunspots, volcano and hiatus effects. The difference of $T_{\mathrm{e}}$ from observed $T_{\mathrm{a}}\left(T_{\text {ambient }}\right)$ noted as DTU ranged from $0 \cdot 163^{\circ} \mathrm{C}$ in 1965 to $2 \cdot 17^{\circ} \mathrm{C}$ in 2012 .

This provided the anthropogenic effect of evapotranspiration arising from swamp cooling by initial humidity increase which in turn is absorbed without heating the air while maintaining the saturation humidity criterion. The 48 years of data are used to develop the correlation of thermal emissions, expressed using estimates for $T_{\mathrm{e}}$ with logarithmic changes in water vapor and carbon dioxide concentrations. This is one of the main GAW convective equations

1. $\log E_{\mathrm{v}}=4 \cdot 78+0 \cdot 0245 T_{\mathrm{e}}-0 \cdot 369 \times \log C$

where $E_{\mathrm{v}}$ is the initial water vapor in the atmosphere in ppm. (This is calculated by adding the increase necessary to bring $T_{\mathrm{e}}$ to $T_{\mathrm{a}}$ by moisture added to a base-specific moisture content of $16466 \mathrm{ppm}$ (for the year 1964). This value for the base year is obtained from courtesy of geographer Ole Humlum's atmospheric-specific humidity correlations which he had derived using values from the year 1850 HadCRUT meteorological database (of UK), graphs shown in his Climate4you website (see http://www.climate4you. com/index.htm, accessed 08/20/2014).) 


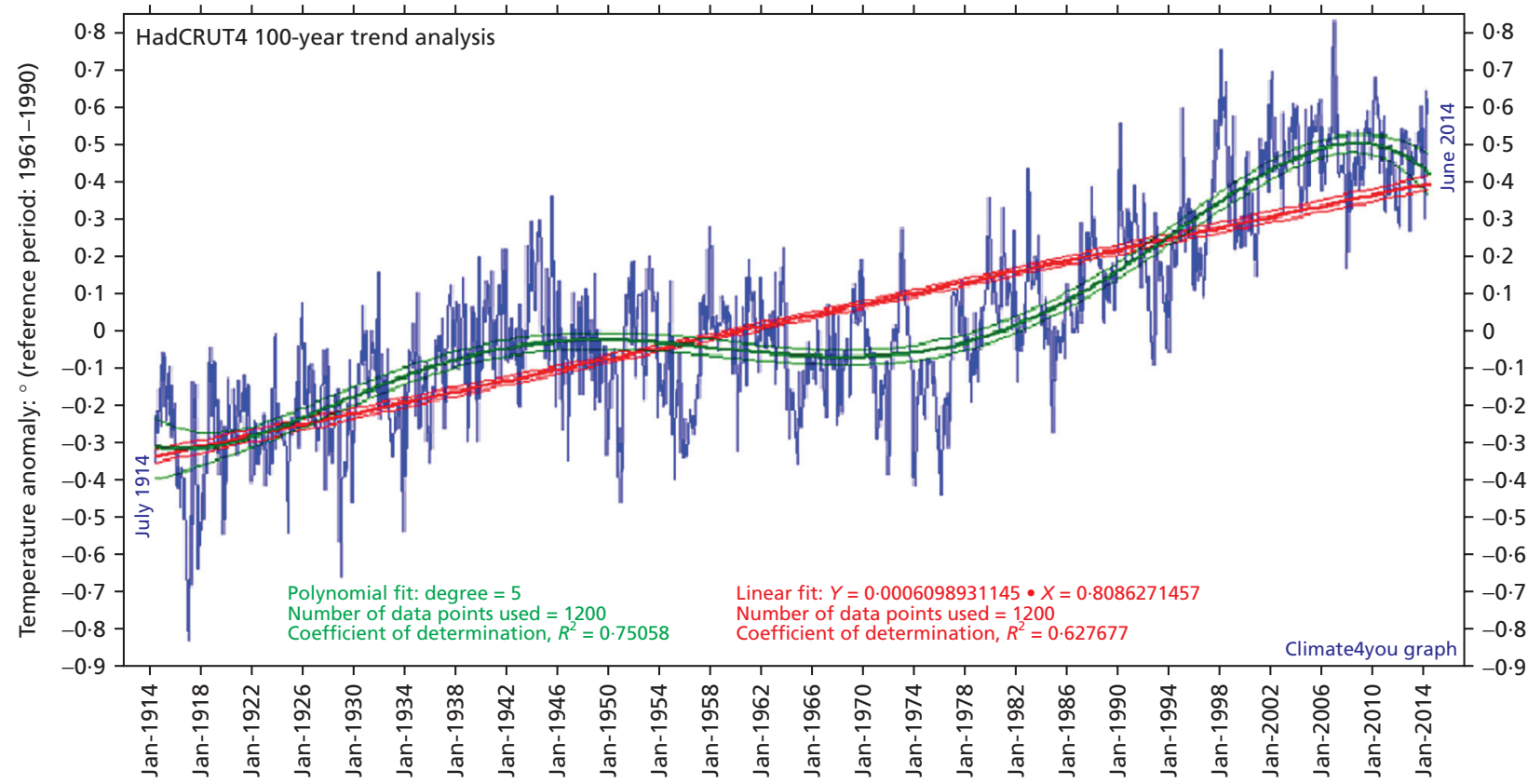

Figure 2. Fifth-order polynomial curve of global mean temperature variation (courtesy of Ole Humlum)

Each year, the calculated $E_{\mathrm{v}}$ was higher than specific average, $W_{\text {s }}$, shown in the HadCRUT curves. This difference is termed as $W_{\text {a }}$ - absorbed water vapor with a concurrent cooling effect - whether from transpiration into plant growth or into the ocean similar to carbon dioxide changes. The authors' model thus shows a correlation for simultaneous evapotranspiration moisture and carbon dioxide. This can then be used to project future changes in atmospheric temperatures using total energy conversions.

The energy conversions using varying proportions of the six different types of energy sources - oil, gas, coal, nuclear, hydro and renewables - can be projected in proportion to population changes and its usage rates. These proportions are used to compute the varying carbon dioxide emissions net amounts at the same $E_{\mathrm{t}}$, total energy, by varying renewable energy. The study analyzed the atmospheric temperature anamolies over the period from 1850 to arrive at a statistically significant correlation.

Thayer Watkins ${ }^{16}$ noted that global mean temperatures showed a cyclic curve of upward increases followed by a period of decreases (similar to recent 'hiatus' data). HadCRUT meteorological data suggested that a fifth-order polynomial is a better trend fit than a straight line which showed low $R^{2}$ values in the curve fits by Humlum's curve - which is shown in Figure 2.

The authors' modeling found that the polynomial fit follows the type $T_{\mathrm{a}^{\prime}}=a+b X+c / X^{2}+d X^{3}-$ a fifth-order polynomial (Figure 2) similar to the one used for expressing specific heats of compounds

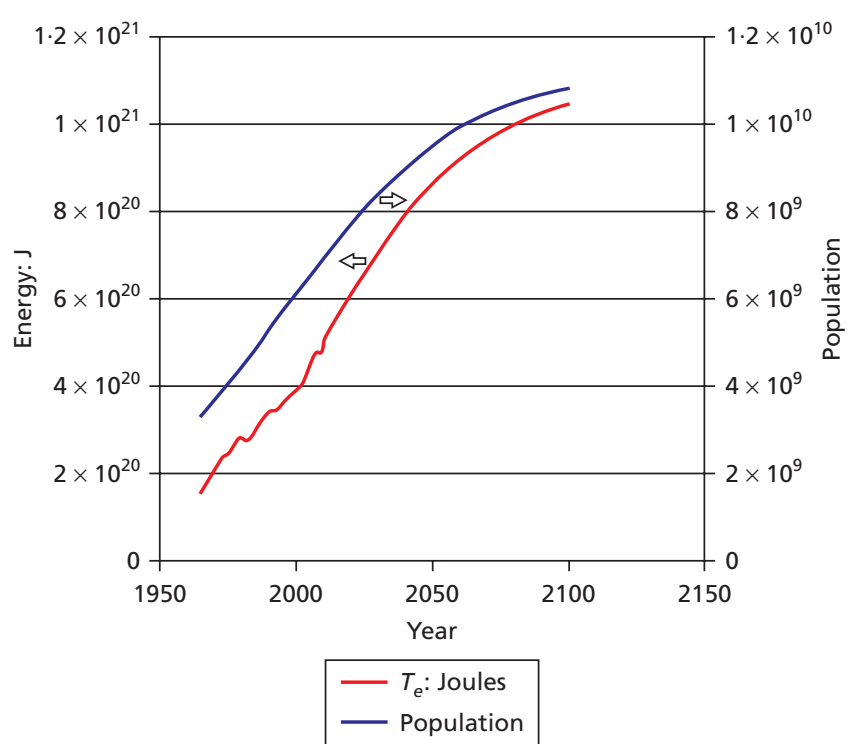

Figure 3. Global population and energy consumption projections Sets $1 / 2$

with temperature. Here $X$ is (year - 1849 base year). Incidentally, the population changes between 1965 and 2012 as well as between 1965 and UN Projections to year 2100 also followed similar fifth-order curve (Figure 3). It is necessary to use a global mean surface temperature, $T_{\mathrm{a}}$, projected by a logical or a trend curve to calculate saturation humidity constraints and then the anticipated 


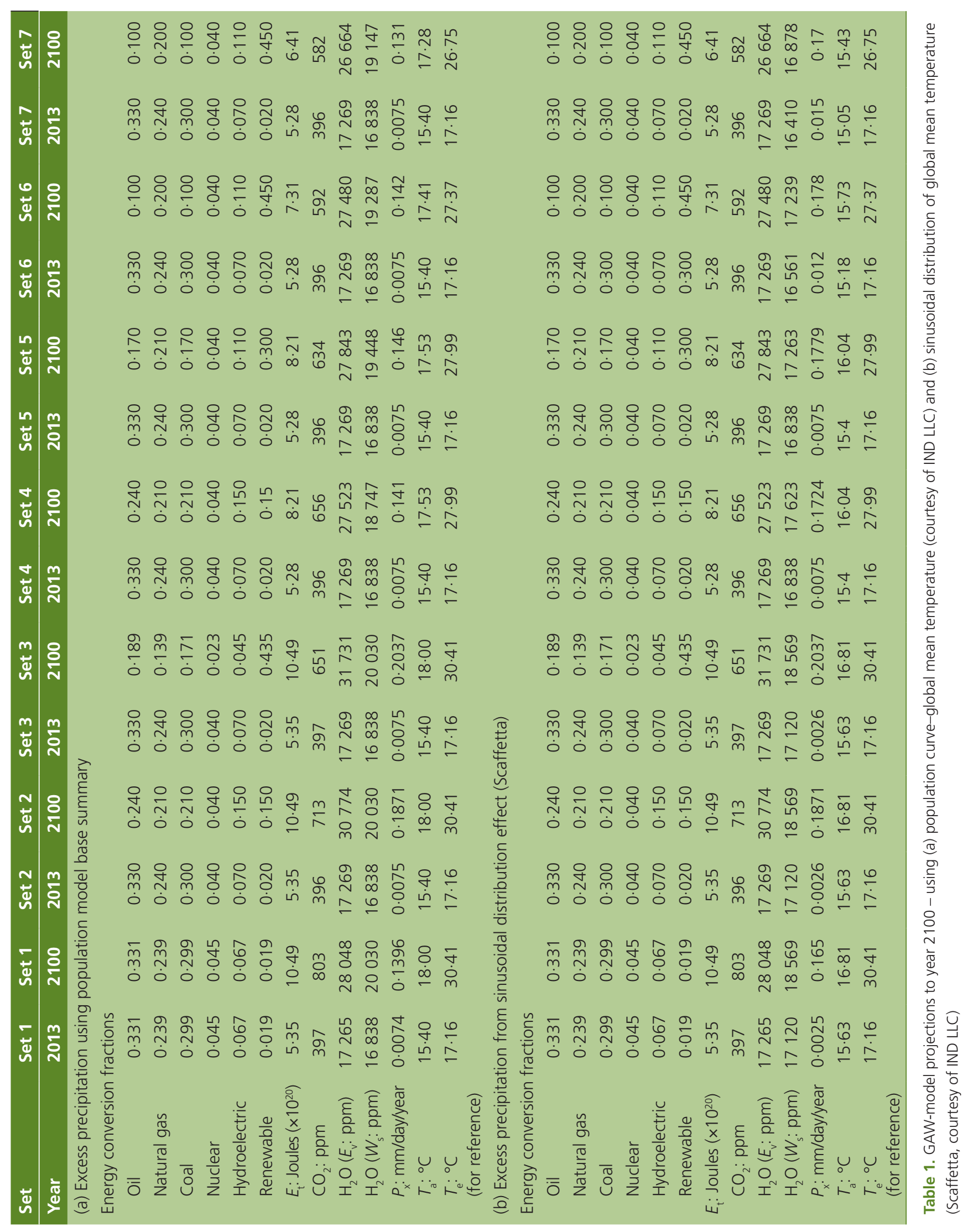


$P_{x}$ - excess precipitation over and above the twentieth century average of $2.7 \mathrm{~mm} /$ day, due to solar insolence. The authors used the $T_{\mathrm{a}^{\prime}}$ projected by this smoothed curve to estimate the global mean temperature anticipated each year to delineate the anticipated $P_{x}$

Scaffetta ${ }^{17}$ noted that the global mean temperature correlation is more of a sinusoidal curve if one were to plot the data estimated during the past 2000-4000 years, including the measured data of the past 150 years. He further noted that the variations in the incoming solar radiation onto Earth surface are very important to consider.

The climate modeling done using high-speed computations seems to keep the solar radiation onto Earth as a constant in computing energy budgets on terrestrial bodies of water causing the latent heat evapotranspiration in published reports. This value is noted as $80 \mathrm{~W} / \mathrm{m}^{2}$ by Trenberth et al. ${ }^{18}$ Stephens et al. ${ }^{19}$ consider this effect to be $88 \pm 10 \mathrm{~W} / \mathrm{m}^{2}$ in explaining the recent observations of temperature pause, while another climate study used an average between these two values. The authors can see that these quantities have much larger variations of over $10 \%$ error, yet there is an insistence of the warming effects from parts per billion changes of man-made events. The elusiveness of measuring water vapor and cloud effects is also adjusted in these models by changing the residence time before precipitation in the radiation-convection models. ${ }^{20}$ It is noted that CMIP5 models use solar radiation data given by SOLARIS in the recent past.

Table 1, provided by courtesy of IND LLC, summarizes the GAW model projections to year 2100, showing the effects of thermal emissions from renewable energy use along with calculated $P_{x}$, compared to base for Set 1 in 2013 or the modified base 2 for the year 2013. Each set shows the effect of a varied proportion of energy conversion sources. These projections are made when none of the thermal air emissions are converted to warming ocean or Earth with non-zero heat capacity - that is, unsequestered atmospheric air heat by water or Earth.

The table summarizes the projected model showing effects of thermal emissions from renewable energy use along with their conclusions. The following are evident from the table: if the world consumes energy per capita as in the past 15 years annual energy consumption can go up to $10.6 \times 10^{20} \mathrm{~J}-$ and the global mean temperature (using a base of $15^{\circ} \mathrm{C}$ ) has the possibility to increase to the same $18^{\circ} \mathrm{C}$ from the present average of $15 \cdot 7^{\circ} \mathrm{C}$ while the carbon dioxide may vary between 803 and 651 ppm (Sets 1 and 3) when the proportion of renewable + hydro + nuclear changes from $13 \cdot 1$ to $50 \cdot 3 \%$ of total energy. If the energy consumption changes due to better energy efficiency, less consumption, interim periods of lower construction (at the same population growth) the global mean temperature can come down from the anticipated $18^{\circ} \mathrm{C}$ at $10.6 \times 1020 \mathrm{~J}$ to $17 \cdot 3^{\circ} \mathrm{C}$ at a lower energy consumption per capita totaling an annual consumption of $6.4 \times 10^{20} \mathrm{~J}$. Higher renewable energy usage only lowers the carbon dioxide but not the global mean temperature.

It is cautioned that these projections on absolute global mean temperatures are subject to variations that may be caused by other major natural causes - such as due to sun-spot variations, abrupt ocean surface temperature cooling which seems to be cyclic, variations in total carbon dioxide absorption-desorption from the oceans (which does not have to be a constant 40 or $45 \%$ as used in simulations) and volcanic eruption cooling effects. However, the GAW is still independent of the source of energy conversions, such as whether it is from fuel combustion or taken from solar or wind or hydro and so on, with the warming directly proportional to the energy value converted. The cumulative effect of additional population growth tends to keep the carbon dioxide levels continuing to grow; it is possible that if all fossil fuel use stopped, the continued warming of atmosphere and the oceans may have carbon dioxide outgassing from the oceans to keep the carbon dioxide- $\mathrm{H}_{2} \mathrm{O}$ vapor combination increasing during the next few centuries.

It is shown that atmospheric mean temperature increase is a function of total anthropogenic energy conversions irrespective of the energy source including renewable alternative energy. While renewable energy may not increase the carbon dioxide levels, it can increase the evapotranspiration and the specific humidity resulting in the same $T_{\mathrm{a}^{\mathrm{a}}}$.

\section{Conclusion}

Human population growth with simultaneous increased energy conversions worldwide will cause more thermal emissions which are inevitable and will increase the evapotranspiration. This is irrespective of the fuel source - causing more precipitation in the future and possible melting of more ocean ice. It is possible to sequester the air temperature increases to divert parts of the emissions to water and non-zero heat capacity of Earth - or do simple sequestration by engineering, such as avoiding airconditioner heat as hot air - but convert to heating Earth with nonzero capacity or into making hot water.

Efforts should be continued in improving the energy efficiencies which will play an important role in moderating the thermal discomforts. The growth of population and corresponding increase in food needs will require fuel-based conversions to supply the botanical carbon cycle along with evapotranspirations. The quest should continue for alternate energy conversion techniques instead of marketing them by fear-based blames on fuel combustion, as the population increase with concurrent energy demands.

Building architecture can be improved to arkitecture (intentional spelling) to facilitate living with rising water levels, which may happen, in the same fashion as buildings have been designed 
to withstand earthquakes for the past 40 years. It is suggested that 'these energy issues' are carried out by laboratory-based experiments like the studies by Hottel on flue gas radiation.

Readers will be interested in an analysis which claimed that the problem is not climate change but population growth, ${ }^{21}$ which is a more generalized statement than a detailed analysis done by IND LLC's modeling.

It is necessary to improve the convective model which helps define the evapotranspiration with an assumed interim air temperature. The authors feel that this can be improved by defining a 'mesh atmosphere' which is a porous radiation shield with emissive vapors and clouds. Such heat transfer computations can be made using furnace design methods of heat transfer resistance in series and parallel, while understanding the difficulties in using average values of averages.$^{22}$ Present-day climate models can improve their techniques by including the effect of human energy conversions, as well as the changes in absolute humidity which are easily computed.

\section{Acknowledgments}

The review efforts by Indra Neelameggham and others are acknowledged. The authors had several communications on the understanding of climate data, modeling and analysis with Ole Humlum, Nicola Scafetta, N. Schafer, Tapio Schneider and countless other climate scientists during their development of the independent model. The authors acknowledge this research being facilitated by IND LLC and appreciate the permissions given by IND LLC, Ole Humlum and Nicola Scaffetta for using charts and tables shown in this paper. The authors also acknowledge the constructive critiques from the climate science reviewer which helped to improve the paper.

\section{REFERENCES}

1. Neelameggham, N. R.; Davis, B. R. Thermal wastes from energy conversions and global anthropogenic warming. In Proceedings of the Energy Technology \& Carbon Dioxide Management Symposium, TMS, 2015, March 17 (Jha, A. et al. (eds.)). New York, NY, USA: Wiley-TMS, 2015, 28-29.

2. Xie, P.; Arkin, P. A. Analysis of global monthly precipitation using gauge observations, satellite estimates, and numerical model predictions, J. Clim. 1996, 9, 840-858.

3. Neelameggham, N. R. 'It is the Water Vapour' and Neale's GAW Model $^{\odot}$. South Jordan, UT, USA: Ind LLC, 2014.

4. Neelameggham, N. R.; Davis, B. R. Heat transfer modelling of global anthropogenic warming, J. Nanomater. Energy. 2014, 3, 149-153.

5. BP Statistical Review of World Energy. BP statistical review of world energy, June 2013. See http://www.bp.com/ statistical_review for further details. Accessed 24/04/2014.
6. Willett, K. M.; Gillett, N. P.; Jones, P. D.; Thorne, P. W. Attribution of observed surface humidity changes to human influence, Nature. 2007, 449, 710-712.

7. Poulter, B.; Frank, D.; Ciais, P.; Myneni, R. B.; Andela, N.; Bi, J.; Broquet, G.; Canadell, J. G.; Chevallier, F.; Liu, Y. Y.; Running, S. W.; Sitch, S.; van der Werf, G. R. The contribution of semi-arid ecosystems to inter annual global carbon cycle variability. Nature. 2014, 509, 600-603.

8. Sverdrup, H. U.; Johnson, M. W.; Fleming, R. H. The Oceans. Their Physics, Chemistry and General Biology. Englewood Cliffs, NJ, USA: Prentice Hall, 1942.

9. Sariemento, J. L. Ocean Biogeochemical Dynamics, Chapter 8. Princeton, NJ, USA: Princeton University Press. See http:// ic.ucsc.edu/ acr/eart254/Ch8.pdf for further details. Accessed 22/07/2015.

10. Hottel, H. C. Heat transmission by radiation from nonluminous gases, Ind. Eng. Chem. 1927, 19, 888-894.

11. Farag, I. Radiative Heat Transfer from Non-Luminous Gases. Computational Study of the Emissivities of Water Vapor and Carbon Dioxide, Table 5.5-1. Doctor of Science Thesis MIT, 1976, p. 202.

12. Nahle, N. S. Determination of the total emissivity of a mixture of gases containing $5 \%$ of water vapor and $0.039 \%$ of carbon dioxide at overlapping absorption bands. See http://www. biocab.org/Overlapping_Absorption_Bands.pdf for further details. Accessed 05/25/2014.

13. Brooks, F. A. Observations on atmospheric radiations. Papers in Physical Oceanography and Meteorology, Vol. VIII, No. 2. Woods Hole, MA, USA: Massachusetts Institute of Technology And Woods Hole Oceanographic Institution, 1941.

14. Manabe, S.; Wetherald, R. T. Thermal equilibrium of the atmosphere with a given distribution of relative humidity, $J$. Atmos. Sci. 1967, 24, 241-259.

15. Covey, C.; Achuta Rao, K. M.; Lambert, S. J.; Taylor, K. E. Intercomparison of Present and Future Climates Simulated by Coupled Ocean-Atmosphere GCMs, PCMDI Report No. 66 UCRL-ID-140325.

16. Watkins, T. An estimation of the period of the cycle in global temperature and the long term trend in global temperature. See http://www.applet-magic.com/AGT_cycle1st.htm for further details. Accessed 09/03/2014.

17. Scaffetta, N. Empirical analysis of the solar contribution to global mean air surface temperature change, J. Atmos. Sol. Terr. Phys. 2009, 71, 1916-1923.

18. Trenberth, K. E.; Fasullo, J. T.; Kiehl, J. Earth's global energy budget, Bull. Am. Meteor. Soc. 2009, 90, 311-323.

19. Stephens, G. L.; Li, J.; Wild, M.; Clayson, C. A.; Loeb, N.; Kato, S.; L'Ecuyer, T.; Stackhouse, P. W., Jr.; Lebsock, M.; Andrews, T. An update on Earth's energy balance in light of the latest global observations. Nat. Geosci. 2012, 5, 691-696.

20. Schaller, N.; Cermak, J.; Wild, M.; Knutti, R. The sensitivity of the modeled energy budget and hydrological cycle to $\mathrm{CO}_{2}$ and solar forcing, Earth Syst. Dyn. 2013, 4, 253-266. 
Nanomaterials and Energy

Volume 4 Issue NME2
Twenty-first century global anthropogenic

warming convective model

Neelameggham and Davis
21. Farrell, P. B. Opinion: climate change isn't the problem. A population bomb is killing us. See http://www.marketwatch. com/story/climate-change-isnt-the-problem-a-populationbomb-is-killing-us-2014-09-23 for further details. Accessed 09/05/2014
22. Christo, F. C.; Krishnamoorthy, L. V. An Experimental and Numerical Study of Infrared Emission from a Porous Radiant Burner, Report DSTO-TR-1154. Victoria, Australia: DSTO-Aeronautical and Maritime Research Laboratory, 2001.

\section{WHAT DO YOU THINK?}

To discuss this paper, please email up to 500 words to the managing editor at nme@icepublishing.com

Your contribution will be forwarded to the author(s) for a reply and, if considered appropriate by the editor-inchief, will be published as a discussion in a future issue of the journal.

ICE Science journals rely entirely on contributions sent in by professionals, academics and students coming from the field of materials science and engineering. Articles should be within 5000-7000 words long (short communications and opinion articles should be within 2000 words long), with adequate illustrations and references. To access our author guidelines and how to submit your paper, please refer to the journal website at www.icevirtuallibrary.com/nme 